\title{
Random equations and its application towards best random proximity point theorems
}

\section{SOMAYYA KOMAL and POOM KUMAM}

\begin{abstract}
.
In this paper best random proximity points equations have been proved. As a result best random proximity points and best random $p$-proximity points have been proposed with the help of new generalized notions. These are generalizations of random fixed point theorems. Also, the concept of random best $p$-proximity points has also be proposed in this work and corresponding theorems are also defined here.
\end{abstract}

\section{REFERENCES}

[1] Basha, S. S., Common best proximity points: global minimal solutions, TOP 21 (2013), No. 1, 182-188

[2] Basha, S. S., Best proximity point theorems generalizing the contraction principle, Nonlinear Anal., 74 (2011), $5844-5850$

[3] Basha, S. S., Best proximity point theorems, J. Approx. Theory, 163 (2011), No. 11, 1772-1781

[4] Chaipunya, P., Sintunavarat, W and Kumam, P., On P-contractions in ordered metric spaces, Fixed Point Theory Appl., 2012, 2012:219, 10 pp.

[5] Fan, K., Extensions of two fixed point theorems of F. E. Browder, Mathematische Zeitschrift, 112 (1969), 234-240

[6] Komal, S. and Kumam, P., A new class of $\mathcal{S}$-contractions in complete metric spaces and $\mathcal{G}_{\mathcal{P}}$-contractions in ordered metric spaces, Fixed Point Theory and Appl., 76 (2016)

[7] Kumam, P. and Plubtieng, S., Random fixed point theorem for multivalued nonexpansive operators in Uniformly nonsquare Banach spaces, Random Operator and Stochastic Equation, 14 (2006), No. 1, 35-44

[8] Omidvari, M., Vaezpour, S. M. and Saadati, R., Best Proximity point Theorems for F-contractive non-self mappings, Miskolc Math. Notes, 15 (2006), No. 2, 615-623

[9] Plubtieng, S. and Kumam, P., Random fixed point theorems for multivalued nonexpansive non-self random operators, J. Appl. Math. Stoch. Anal., (2006), Article ID43796, Pages 1-9

[10] Ta Ngoc Anh, Random equations and applications to general random fixed point theorem, Newzealand J. Math., 41 (2011), 17-24

\footnotetext{
Department of Mathematics \& Theoretical and Computational Science (TACS) CEnTER

SCIENCE LABORATORY BUILDING, FACULTY OF SCIENCE

KING MONGKUT'S University OF TECHNOLOGY THONBURI (KMUTT)

126 Pracha Uthit RD. BANGmod, Thung Khru, BANGKoK, 10140, Thailand

E-mail address: somayya.komal@mail.kmutt.ac.th

E-mail address: poom.kumamemail.kmutt.ac.th
}

Received: 25.07.2017; In revised form: 08.06.2018; Accepted: 15.06.2018

2010 Mathematics Subject Classification. 58C30, 47H10.

Key words and phrases. Best random proximity point, Random fixed point. Best random p-proximity point, $\mathcal{G}_{\mathcal{P}^{-}}$ function, Random $\mathcal{G}_{\mathcal{P}}$-contraction, $P$-property.

Corresponding author: Poom Kumam; poom.kumam@mail.kmutt.ac.th 